\title{
Clinical features of ST-segment elevation myocardial infarction in young Chinese patients
}

\author{
Yunjuan Sun, Jialiang Xu, Zhisong He, Xujie Cheng, Tingbo Jiang \\ Department of Cardiology, the First Affiliated Hospital of Soochow University, \\ Suzhou, Jiangsu Province, People's Republic of China
}

\begin{abstract}
Background: To investigate the clinical characteristics, angiographic findings and clinical outcomes (in-hospital) of young adults with acute myocardium infarction in a Chinese population.

Methods: This was an observational study. Five hundred and forty-nine patients who suffered with ST-segment elevation myocardial infarction (STEMI) firstly between January 2013 and December 2015 were enrolled consecutively. All patients were divided into two groups: "young group" patients were $\leq 50$ years old; and "non-young group" patients were $>50$ years old. Clinical features were compared, angiographic findings and clinical outcomes were observed between the two groups.

Results: There were 131 and 418 patients included in the young group and the non-young group, respectively. Twenty-eight patients suffered deaths during the hospital stay and only one death occurred in the young group. Compared with non-young group, the young group was associated with male, smoke, fewer chronic diseases, Killip class I on admission, lower level of $\mathrm{N}$-terminal pro B-type natriuretic peptide (NT-proBNP), higher level of triglyceride and lower level of high-density lipoprotein cholesterol $(H D L-C)$, single-vessel lesion and intracoronary thrombus $(p<0.005)$. The average length of hospital stay of non-young group was 1.5 days longer than the young group. Compared with the non-young group, the young group inclined not to use or use only one stent $(p=0.026)$. Multivariable logistic regression analysis showed that older age, shorter hospital stay, advanced Killip class III/IV, increased white blood cell and NT-proBNP were independent risk factors for survival in acute STEMI patients during hospitalization $(p<0.005)$.

Conclusions: Compared with non-young group, the young group was associated with male, smoke, higher level of triglyceride and lower level of $H D L-C$. The condition of patients in young group were relatively mild and the risk of death during hospitalization was lower than the other group. (Cardiol J )
\end{abstract}

Key words: ST-segment elevation myocardial infarction, young, clinical feature, Chinese

\section{Introduction}

During the last decades, cardiovascular disease has become the single largest cause of death in the worldwide [1]. Although mortality in coronary heart disease has markedly reduced in Western societies over the past few decades [2], while the age-adjusted death rate is still increasing in many low- and middle-income countries [3]. Coronary heart disease is emerging as a large and growing burden in China. Data from the China health statistics year book 2020 has shown that coronary heart disease accounted for almost $80 \%$ of overall cardiovascular deaths [4]. Acute myocardial infarc-

Address for correspondence: Tingbo Jiang, MD, PhD, Department of Cardiology, the First Affiliated Hospital of Soochow University, Suzhou, Jiangsu Province, 215006, People's Republic of China, tel/fax: (86)0512-67972087, e-mail: 18906201122@189.cn

Received: 24.10.2019 Accepted: 22.05.2021 Early publication date: 9.06.2021

This article is available in open access under Creative Common Attribution-Non-Commercial-No Derivatives 4.0 International (CC BY-NC-ND 4.0) license, allowing to download articles and share them with others as long as they credit the authors and the publisher, but without permission to change them in any way or use them commercially. 
tion (AMI) is the leading cause of death of patients hospitalized for cardiovascular disease. This new health problem is mostly due to the transition of socioeconomics and individual lifestyle, including urban migration patterns, rapid urban modernization, unhealthy dietary changes, increased tobacco use, and less physical inactivity [3, 4]. The summary exposure values for high body mass index, high blood pressure, high fasting plasma glucose and high low-density lipoprotein cholesterol (LDL-C) increased year by year in the young population from 1990 to 2017 [3]. Coronary heart disease afflicts a younger population and increased deaths of the working-age population. The clinical features and outcomes of AMI in the young population are considered to be different from those in the non-young population. However, there is few data to address these issues in the Chinese population. Therefore, we sought to investigate the clinical characteristics, angiographic findings and clinical outcomes (in-hospital) of young adults with AMI in a Chinese population.

\section{Methods}

\section{Study design}

This is an observational study. All patients who suffered from ST-segment elevation myocardial infarction (STEMI) firstly between January 2013 and December 2015 were enrolled consecutively. Patients who did not immediately receive coronary angiography were excluded. STEMI is defined as patients with persistent chest discomfort or other symptoms suggestive of myocardial ischemia and electrocardiographic ST-segment elevation in at least two contiguous leads (12-lead electrocardiogram), and subsequent release of biomarkers of myocardial necrosis, including creatine kinase isomer-MB and troponin I. After the attack of symptoms of myocardial ischemia, patients were admitted to Chest Pain Center of the documented hospital as soon as possible. Once the diagnosis was considered, green channel was opened immediately. Most patients received primary percutaneous coronary intervention (PCI) except a few of them refused it for their own reasons or did not survive to receive this procedure. This study was conducted in accordance with the amended Declaration of Helsinki, and the protocol was approved by the Institutional Review Boards.

\section{Patients}

Finally, 549 eligible patients were enrolled from the Chest Pain Center during this period. All of the patients were divided into two groups: the "young group" in which patients were $\leq 50$ years old; and the "non-young group" in which patients were $>50$ years old. Managements for all of the patients were given according to individual clinical condition.

\section{PCI procedures}

Percutaneous coronary intervention was performed using standard techniques. A transradial approach using a 6 -F arterial sheath was performed routinely, unless bilaterally upper extremity arteries tortuosity, stenosis or occlusion leading to guiding failed to pass through. An off-line, computer-based software (Innova 2100 Digital Cardiovascular System Revolution of Cardiology, USA) was used for quantitative coronary angiographic analysis. Significant coronary artery stenosis was defined as at least a $75 \%$ reduction in the internal diameter of the left anterior descending, left circumflex or right coronary artery and their major branches, or a $50 \%$ reduction in the internal diameter of the left main trunk assessed visually during coronary angiography. Multivessel disease was defined as the presence of a significant coronary artery atherosclerotic stenosis $(\geq 70 \%$ diameter stenosis) in at least two arteries or a $\geq 50 \%$ diameter stenosis of the left main coronary artery (left main disease) with additional significant stenosis ( $\geq$ $70 \%$ diameter stenosis) of at least one other coronary artery. Gensini score, integrating the degree and locations of stenosis, was applied to analyze the severity of coronary artery disease. Thrombolysis in Myocardial Infarction (TIMI) flow grades in the culprit coronary artery were confirmed at the beginning and end of the procedure. The former-TIMI was defined as the TIMI flow grade recorded before PCI, and the latter-TIMI as the TIMI flow grade recorded after PCI. Choices concerning whether or not to implant stents, bare-metal or drug-eluting type and other interventional measures were left to the discretion of the interventional cardiologist. Intracoronary thrombus was defined as $\geq 1$ filling defect at the site of lesion in the absence of a major dissection. Transcatheter thrombus aspiration was used in patients with massive thrombus in coronary arteries which resulted in blood flow obviously slow or even occluded. Intra-aortic balloon pump was used to support the circulation in patients experiencing cardiogenic shock and performed before, during or after PCI. Patients with severe atrioventricular block were implanted with temporary pacemakers. PCI success was defined as a combination of TIMI flow grade resumed to 3 of 
distal portion of coronary arteries and the residual diameter stenosis $\leq 30 \%$ after procedure.

Ticagrelor (180 mg loading dose) or clopidogrel (300-600 mg loading dose) was given to patients undergoing primary $\mathrm{PCI}$ in the emergency room before cardiac catheterization. And then ticagrelor ( $180 \mathrm{mg} /$ day) or clopidogrel $(75 \mathrm{mg} /$ day $)$ was maintained each day. After $300 \mathrm{mg}$ loading dose, acetylsalicylic acid (100 mg orally once daily) was given identically to each patient.

\section{Definitions and outcomes}

Detailed personal information, including age, gender, marital status, past medical history of hypertension, diabetes mellitus, stroke, smoking and drinking, was collected at the time of admission. Systolic blood pressure, diastolic blood pressure, heart rate and Killip score were all evaluated at the same time. Laboratory parameters were tested at the next morning after admission. N-terminal pro B-type natriuretic peptide (NT-proBNP) was evaluated within $72 \mathrm{~h}$ after PCI. Left ventricular ejection fraction was assessed by transthoracic echocardiography within $72 \mathrm{~h}$ after primary PCI.

In-hospital outcomes included length of hospital stay, all-cause mortality (non-cardiac and cardiac death), major adverse cardiac event (MACE) and hemorrhage. MACE defined as a composite endpoint of infection, stroke, target vessel revascularization, new onset atrial fibrillation, severe atrioventricular block, sustained ventricular tachycardia/fibrillation, left ventricular mural thrombosis, ventricular rupture, congestive heart failure and in-hospital death. Bleeding mainly contained visceral hemorrhage and iatrogenic hemorrhage caused by operations.

\section{Statistical analysis}

Descriptive data for continuous variables with Gaussian distribution were presented as the mean \pm standard deviation (SD). Descriptive data for discrete variables were presented as the frequency (percentage). Patient characteristics were compared between the young and non-young groups using the independent Student t test, $\chi^{2}$ test, or the Fisher exact test as appropriate. Survival curves were calculated by the Kaplan-Meier method and compared using a log-rank test. Univariate logistic regression analyses were performed to identify variables related to MACE during in-hospital time. All variables with a $\mathrm{p}<0.05$ were then tested in a forward stepwise multivariate logistic regression analysis. Data were expressed as hazard ratio with $95 \%$ confidence interval. A $\mathrm{p}$ value $<0.05$ was considered to indicate statistical significance. All analyses were performed using SPSS 13.0 software (SPSS Inc., Chicago, IL, USA).

\section{Results}

Among all of the patients, there were 131 and 418 patients in the young group and the non-young group, respectively. Table 1 showed the baseline clinical characteristics of the patients. Male sex, smoke/current smoker, Killip class I at presentation, lower diastolic blood pressure and higher heart rate were more frequently observed in the young group. In contrast, hypertension and stroke were more frequently observed in the non-young group. Medication at discharge as shown in Table 1 did not differ significantly between the two groups.

Comparisons of laboratory parameters between the young group and non-young group were shown in Table 2. The young group patients had significantly higher counts of white blood cell and platelet, as well as level of hemoglobin and triglyceride (Ps $<0.05)$. Non-young group patients had significantly high-density lipoprotein cholesterol (HDL-C), urea, creatinine and $\mathrm{Lg}$ proBNP $(\mathrm{Ps}<0.05)$. There were no differences between the two groups in uric acid, LDL-C, non-HDL-C, fasting blood glucose, C-reactive protein or troponin I.

Comparisons of the angiographic findings, procedural details and interventional strategies were shown in Table 3. One patient died of cardiac rupture just after radial artery puncture during coronary angiography. Gensini score in both groups did not differ significantly $(\mathrm{p}=0.089)$. The young group patients were more likely to have had single vessel disease than the non-young group patients. The percentages of intracoronary thrombus in the young group and the non-young group were $39.7 \%$ and $29.3 \%(\mathrm{p}=0.025)$. Rates of PCI in both groups were greater than $95 \%$. The average time period from symptom onset to PCI of diseased vessels of the all patients was $128.28 \pm 96.24 \mathrm{~min}$. Patients from the non-young group were more inclined to undergo PCI of a culprit lesion than patients from the young group $(\mathrm{p}=0.022)$. No use of stent was more frequently observed in the young group. Compared with the non-young group, the young group inclined not to use or use only one stent $(\mathrm{p}=0.026)$. Mean stent diameter in the young group was likely larger than that in the non-young group $(\mathrm{p}=0.061)$.

Table 4 showed the in-hospital outcomes for the two groups. There were 28 deaths during hospitalization. Only 1 death occurred in the young group 
Table 1. Patients characteristics.

\begin{tabular}{|c|c|c|c|c|}
\hline Patients characteristics & $\begin{array}{c}\text { All } \\
(n=549)\end{array}$ & $\begin{array}{l}\text { Young group } \\
\text { (n=131) }\end{array}$ & $\begin{array}{l}\text { Non-young group } \\
\text { (n= 418) }\end{array}$ & $\mathbf{P}$ \\
\hline Age [years] & $60.43 \pm 13.36$ & $42.50 \pm 6.33$ & $66.05 \pm 9.46$ & 0.000 \\
\hline Death & $28(5.1 \%)$ & $1(0.8 \%)$ & $27(6.5 \%)$ & 0.010 \\
\hline Male & $476(86.7 \%)$ & $125(95.4 \%)$ & $351(84.0 \%)$ & 0.000 \\
\hline Not-married & $14(2.6 \%)$ & $7(5.3 \%)$ & $7(1.7 \%)$ & 0.490 \\
\hline \multicolumn{5}{|l|}{ Risk factor: } \\
\hline Hypertension & $330(60.1 \%)$ & $46(35.1 \%)$ & $284(67.9 \%)$ & 0.000 \\
\hline Diabetes & $111(20.2 \%)$ & $21(16.0 \%)$ & $90(21.5 \%)$ & 0.171 \\
\hline Current smoker & $348(63.4 \%)$ & $107(81.7 \%)$ & $241(57.7 \%)$ & 0.000 \\
\hline Smoke & $375(68.3 \%)$ & $109(83.2 \%)$ & $266(63.6 \%)$ & 0.000 \\
\hline Gout & $14(2.6 \%)$ & $1(0.8 \%)$ & $13(3.1 \%)$ & 0.205 \\
\hline Stroke & $36(6.6 \%)$ & $2(1.5 \%)$ & $34(8.1 \%)$ & 0.008 \\
\hline Killip class: & & & & 0.022 \\
\hline I & $437(79.6 \%)$ & $116(88.5 \%)$ & $321(76.8 \%)$ & \\
\hline ॥ & $76(13.8 \%)$ & $12(9.2 \%)$ & $64(15.3 \%)$ & \\
\hline III & $9(1.6 \%)$ & $1(0.8 \%)$ & $8(1.9 \%)$ & \\
\hline IV & $27(4.9 \%)$ & $2(1.5 \%)$ & $25(6.0 \%)$ & \\
\hline Left ventricular ejection [mm] & $48.53 \pm 9.78$ & $49.04 \pm 10.33$ & $48.36 \pm 9.59$ & 0.498 \\
\hline \multicolumn{5}{|l|}{ Location of infarction: } \\
\hline Anterior & $204(37.2 \%)$ & $49(37.4 \%)$ & $155(37.1 \%)$ & 0.611 \\
\hline Inferior & $211(38.4 \%)$ & $44(33.6 \%)$ & $167(40.0 \%)$ & \\
\hline Lateral & $7(1.3 \%)$ & $2(1.5 \%)$ & $5(1.2 \%)$ & \\
\hline Extensive anterior wall & $107(19.5 \%)$ & $31(23.7 \%)$ & $76(18.2 \%)$ & \\
\hline Other & $20(3.6 \%)$ & $5(3.8 \%)$ & $15(3.6 \%)$ & \\
\hline Systolic blood pressure [mmHg] & $121.47 \pm 22.99$ & $124.04 \pm 20.74$ & $120.67 \pm 23.61$ & 0.143 \\
\hline Diastolic blood pressure $[\mathrm{mmHg}]$ & $75.53 \pm 14.90$ & $79.08 \pm 15.38$ & $74.41 \pm 14.59$ & 0.002 \\
\hline Heart rate $[\mathrm{bpm}]$ & $80.87 \pm 16.81$ & $83.42 \pm 16.64$ & $80.07 \pm 16.80$ & 0.046 \\
\hline \multicolumn{5}{|l|}{ Medication at discharge: } \\
\hline Acetylsalicylic acid & $506(97.3 \%)$ & $128(98.5 \%)$ & $378(96.9 \%)$ & 0.534 \\
\hline Clopidogrel/ticagrelor & $503(96.7 \%)$ & $125(96.2 \%)$ & $378(96.9 \%)$ & 0.776 \\
\hline Statins & $514(98.8 \%)$ & $129(99.2 \%)$ & $385(98.7 \%)$ & 1.000 \\
\hline Beta-blocker & $437(84.0 \%)$ & $108(83.1 \%)$ & $329(84.4 \%)$ & 0.730 \\
\hline ACEI/ARB & $324(62.3 \%)$ & $81(62.3 \%)$ & $243(62.3 \%)$ & 1.000 \\
\hline Calcium channel blocker & $18(3.5 \%)$ & $7(5.3 \%)$ & $11(2.8 \%)$ & 0.172 \\
\hline Diuretics & $40(7.7 \%)$ & $7(5.4 \%)$ & $33(8.5 \%)$ & 0.254 \\
\hline Digoxin & $14(2.7 \%)$ & $1(0.8 \%)$ & $13(3.3 \%)$ & 0.206 \\
\hline Spirolactone & $139(26.7 \%)$ & $40(30.8 \%)$ & $99(25.4 \%)$ & 0.230 \\
\hline Warfarin & $7(1.3 \%)$ & $3(2.3 \%)$ & $4(1.0 \%)$ & 0.303 \\
\hline
\end{tabular}

ACEI/ARB - angiotensin converting enzyme inhibitor/angiotensin receptor blocker

for which the cause was of cardiogenic shock. The other 27 deaths occurred in the non-young group, including 11 for cardiogenic shock, 9 for ventricular rupture, 3 for malignant ventricular arrhythmia, 2 for pericardial tamponade, 1 for cerebrovascular accident and 1 for electrical mechanical dissociation. The young group had a shorter length of hospital stay than the non-young group. And the frequency of infection and congestive heart failure were less common observed in the young group. 
Table 2. Laboratory parameters.

\begin{tabular}{|c|c|c|c|c|c|c|c|}
\hline Laboratory parameter & & All & & Young group & & $\begin{array}{l}\text { Non-young } \\
\text { group }\end{array}$ & $\mathbf{P}$ \\
\hline Hemoglobin $[\mathrm{g} / \mathrm{L}]$ & 504 & $138.19 \pm 20.36$ & 121 & $148.10 \pm 13.55$ & 383 & $135.06 \pm 21.15$ & 0.000 \\
\hline White blood cell $\left[10^{9} / \mathrm{L}\right]$ & 505 & $10.69 \pm 3.53$ & 121 & $11.69 \pm 3.40$ & 384 & $10.37 \pm 3.52$ & 0.000 \\
\hline Platelet $\left[10^{9} / \mathrm{L}\right]$ & 505 & $204.13 \pm 65.08$ & 121 & $226.36 \pm 60.41$ & 384 & $197.93 \pm 64.99$ & 0.000 \\
\hline Uric acid $[\mu \mathrm{umol} / \mathrm{L}]$ & 542 & $346.38 \pm 113.95$ & 131 & $347.78 \pm 111.53$ & 411 & $345.93 \pm 114.84$ & 0.870 \\
\hline $\mathrm{TC}[\mathrm{mg} / \mathrm{dL}]$ & 540 & $4.54 \pm 1.10$ & 130 & $4.60 \pm 1.12$ & 410 & $4.52 \pm 1.09$ & 0.516 \\
\hline LDL-C [mg/dL] & 540 & $2.90 \pm 0.96$ & 130 & $2.99 \pm 0.99$ & 410 & $2.87 \pm 0.95$ & 0.230 \\
\hline $\mathrm{HDL}-\mathrm{C}[\mathrm{mg} / \mathrm{dL}]$ & 540 & $1.07 \pm 0.23$ & 130 & $1.02 \pm 0.19$ & 410 & $1.09 \pm 0.24$ & 0.001 \\
\hline Triglyceride [mg/dL] & 539 & $1.58 \pm 1.57$ & 130 & $2.02 \pm 1.74$ & 409 & $1.44 \pm 1.49$ & 0.000 \\
\hline Non-HDL-C [mg/dL] & 540 & $3.47 \pm 1.07$ & 130 & $3.58 \pm 1.09$ & 410 & $3.43 \pm 1.06$ & 0.178 \\
\hline FBG [mmol/L] & 540 & $6.92 \pm 3.14$ & 130 & $6.51 \pm 2.79$ & 410 & $7.05 \pm 3.24$ & 0.062 \\
\hline hs-CRP [mg/L] & 542 & $7.69 \pm 4.75$ & 131 & $7.27 \pm 4.54$ & 411 & $7.83 \pm 4.81$ & 0.228 \\
\hline Urea $[\mathrm{mmol} / \mathrm{L}]$ & 544 & $5.61 \pm 2.45$ & 131 & $4.71 \pm 1.47$ & 413 & $5.90 \pm 2.62$ & 0.000 \\
\hline Creatinine $[\mu \mathrm{mol} / \mathrm{L}]$ & 545 & $80.83 \pm 40.38$ & 131 & $70.04 \pm 15.89$ & 414 & $84.24 \pm 44.94$ & 0.000 \\
\hline Troponin I [pg/mL] & 499 & $49.98 \pm 30.27$ & 118 & $49.62 \pm 29.89$ & 381 & $50.09 \pm 30.43$ & 0.881 \\
\hline Lg pro-BNP & 396 & $3.03 \pm 0.52$ & 92 & $2.78 \pm 0.55$ & 304 & $3.10 \pm 0.49$ & 0.000 \\
\hline
\end{tabular}

BNP — B-type natriuretic peptide; FBG — fasting blood glucose; HDLC — high-density lipoprotein cholesterol; hs-CRP — high sensitivity reactive protein; LDL-C — low-density lipoprotein cholesterol; TC — total cholesterol

There were no differences in the MACE between the two groups. There was a significant difference in the cumulative survival rates between the two groups during hospitalization ( $\mathrm{p}=0.015$, Fig. 1 ). Multivariable logistic regression analysis showed that older age, shorter hospital stay, advanced Killip class III/IV, increased white blood cell and NT-proBNP were independent risk factors for survival in acute STEMI patients during hospitalization $(\mathrm{p}<0.005$, Table 5).

\section{Discussion}

In this study, clinical characteristics of STEMI among 131 young patients ( $\leq 50$ years old) and 418 non-young patients ( $>50$ years old) were compared. When comparing the groups, the young group patients were associated with male sex, smoke/current smoke, lower Killip class, hyperlipidemia, higher level of hemoglobin, lower level of NT-proBNP. Single diseased vessel, intracoronary thrombus and single stent implant were more common in the young group. Infection, congestive heart failure and mortality were lower in the young group compared to the non-young group.

Previous studies reported that the young AMI patients had a higher proportion of males and current smokers than non-young patients [5-11]. The findings of the present study were in accordance with these studies. Smoking accounts for $80 \%$ to $90 \%$ of young AMI patients and was emerging as the main coronary risk factor $[6,7,12]$. In contemporary society, two-thirds of Chinese males smoked. Among Chinese women, however, there has been a tenfold intergenerational reduction in smoking uptake rates. The tobacco-attributed proportion was increasing in men, but was low and decreasing, in women [13]. Therefore, smoke was more prevalent in young Chinese patients than older ones. Former researchers have reported that the prevalence of chronic diseases, such as hypertension, diabetes mellitus and stroke in the young patients were lower in the young patients than that in the non-young patients $[6,8,10,11,14$, 15]. In the present study, the prevalence of chronic disease was also in accordance with these trends, although the diabetes mellitus was not significant.

It was interesting that it was found the young STEMI patients had a significantly higher level of triglyceride and lower level of HDL-C than that of the older patients, while total cholesterol and LDL-C did not differ significantly. The latest studies also indicated that young patients with STEMI had a higher level of non-HDL-C and triglyceride $[16,17]$. In a modern lifestyle, the increased level of triglyceride might be associated with decreased physical activity and increased fat mass [18]. Triglyceride-rich lipoproteins are associated with 
Table 3. Angiographic findings and intervention.

\begin{tabular}{|c|c|c|c|c|}
\hline Patient characteristics & All & Young group & Non-young group & $\mathbf{P}$ \\
\hline $\mathrm{PCl}$ & $541(98.5 \%)$ & $126(96.2 \%)$ & $415(99.3 \%)$ & 0.022 \\
\hline Gensini score & $54.88 \pm 30.38$ & $51.18 \pm 27.57$ & $56.04 \pm 31.15$ & 0.089 \\
\hline Number of diseased vessels: & & & & 0.000 \\
\hline 1 & $314(57.3 \%)$ & $97(74.0 \%)$ & $217(52.0 \%)$ & \\
\hline 2 & $155(28.3 \%)$ & $25(19.1 \%)$ & $130(31.2 \%)$ & \\
\hline 3 & $79(14.4 \%)$ & $9(6.9 \%)$ & $70(16.8 \%)$ & \\
\hline Intracoronary thrombus & $174(31.8 \%)$ & $52(39.7 \%)$ & $122(29.3 \%)$ & 0.025 \\
\hline Time period from symptom onset to $\mathrm{PCl}$ [min] & $128.28 \pm 96.24$ & $129.71 \pm 87.50$ & $127.85 \pm 98.82$ & 0.853 \\
\hline Initial TIMI: & & & & 0.554 \\
\hline 0 & $417(76.1 \%)$ & $94(71.8 \%)$ & $323(77.5 \%)$ & \\
\hline 1 & $19(3.5 \%)$ & $5(3.8 \%)$ & $14(3.4 \%)$ & \\
\hline 2 & $51(9.3 \%)$ & $15(11.5 \%)$ & $36(8.6 \%)$ & \\
\hline 3 & $61(11.1 \%)$ & $17(13.0 \%)$ & $44(10.6 \%)$ & \\
\hline After TIMI: & & & & 0.219 \\
\hline 0 & $4(0.7 \%)$ & 0 & $4(1.0 \%)$ & \\
\hline 1 & $4(0.7 \%)$ & 0 & $4(1.0 \%)$ & \\
\hline 2 & $27(5.0 \%)$ & $3(2.4 \%)$ & $24(5.8 \%)$ & \\
\hline 3 & $505(93.5 \%)$ & $124(97.6 \%)$ & $381(92.3 \%)$ & \\
\hline After-initial TIMI & $2.37 \pm 1.11$ & $2.35 \pm 1.10$ & $2.37 \pm 1.11$ & 0.863 \\
\hline Stent: & & & & 0.026 \\
\hline 0 & $132(24.1 \%)$ & $39(29.8 \%)$ & $93(22.3 \%)$ & \\
\hline 1 & $397(72.4 \%)$ & $91(69.5 \%)$ & $306(73.4 \%)$ & \\
\hline 2 & $19(3.5 \%)$ & $1(0.8 \%)$ & $18(4.3 \%)$ & \\
\hline \multicolumn{5}{|l|}{ Stent type: } \\
\hline Mean total stent length [mm] & $23.87 \pm 7.12$ & $23.37 \pm 6.59$ & $24.01 \pm 7.27$ & 0.445 \\
\hline Mean stent diameter [mm] & $2.99 \pm 0.34$ & $3.05 \pm 0.33$ & $2.97 \pm 0.35$ & 0.061 \\
\hline Bare metal stent use & $37(8.9 \%)$ & $8(8.7 \%)$ & $29(9.0 \%)$ & 1.000 \\
\hline Drug-eluting stent use & $379(91.1 \%)$ & $84(91.3 \%)$ & $295(91.0 \%)$ & \\
\hline Transcatheter thrombus aspiration & $63(11.5 \%)$ & $20(15.3 \%)$ & $43(10.3 \%)$ & 0.156 \\
\hline
\end{tabular}

$\mathrm{PCl}$ - percutaneous coronary intervention; TIMI — Thrombolysis in Myocardial Infarction

increased rates of progression of atherosclerotic lesions [19]. During the progression of atherosclerosis, inflammatory cells destabilize lipid-rich plaques in the arterial wall and cause their ruptures, thus triggering myocardial infarction and stroke [20]. The findings of the current study also confirmed that the count of white blood cells and the level of triglyceride were both increased in the young group. Thus, it may be a warning to pay more attention to the level of triglyceride in young patients. Progressively reducing the level of triglyceride would benefit young adults in the prevention of cardiovascular events.

In the present study, the percentage of PCI and the use of stents were lower in the young group than that in the non-young group. It might have been related to many factors, such as not severe residual stenosis of culprit coronary artery, high-burden intracoronary thrombus, coronary vasospasm and individual choice [6]. It was found that single-vessel lesion and intracoronary thrombus were much more common in young patients. And, Gensini score in the young group seemed lower than that in the non-young group, though not significant. These findings were consistent with previous studies and explained reasons of the relatively low utilization rate of stent [17]. Young patients had a higher probability of angiographically normal or mildly obstructed coronary arteries than their older counterparts [7]. 
Table 4. In-hospital outcome.

\begin{tabular}{lcccc}
\hline & All & Young group & Non-young group & P \\
\hline Length of hospital stay [day] & $9.49 \pm 7.38$ & $8.36 \pm 3.54$ & $9.84 \pm 8.12$ & 0.004 \\
Motality & $28(5.1 \%)$ & $1(0.8 \%)$ & $27(6.5 \%)$ & 0.006 \\
Bleeding & $16(2.9 \%)$ & $2(1.5 \%)$ & $14(3.3 \%)$ & 0.381 \\
Infection & $54(9.8 \%)$ & $5(3.8 \%)$ & $49(11.7 \%)$ & 0.007 \\
Stroke & $4(0.7 \%)$ & 0 & $4(1.0 \%)$ & 0.577 \\
Stent thrombosis & $5(0.9 \%)$ & $2(1.5 \%)$ & $3(0.7 \%)$ & 0.343 \\
New onset of atrial fibrillation & $35(6.4 \%)$ & $4(3.1 \%)$ & $31(7.4 \%)$ & 0.099 \\
New onset of atrial ventricular block & $37(6.7 \%)$ & $6(4.6 \%)$ & $31(7.4 \%)$ & 0.321 \\
Sustained VT/VF & $43(7.8 \%)$ & $9(6.9 \%)$ & $34(8.1 \%)$ & 0.713 \\
Left ventricular thrombus & $6(1.1 \%)$ & $3(2.3 \%)$ & $3(0.7 \%)$ & 0.151 \\
Ventricular rupture & $10(1.8 \%)$ & 0 & $10(2.4 \%)$ & 0.128 \\
Congestive heart failure & $98(17.9 \%)$ & $11(8.4 \%)$ & $87(20.8 \%)$ & 0.001 \\
Ventricular aneurysm & $27(4.9 \%)$ & $5(3.8 \%)$ & $22(5.3 \%)$ & 0.646 \\
Hypotension & $99(18.0 \%)$ & $19(14.5 \%)$ & $80(19.1 \%)$ & 0.229 \\
Acute hepatic/renal dysfunction & $31(5.6 \%)$ & $7(5.3 \%)$ & $24(5.7 \%)$ & 1.000 \\
Required blood transfusion & $3(0.5 \%)$ & 0 & $3(0.7 \%)$ & 1.000 \\
\hline
\end{tabular}

VT/VF — ventricular tachycardia/ventricular fibrillation

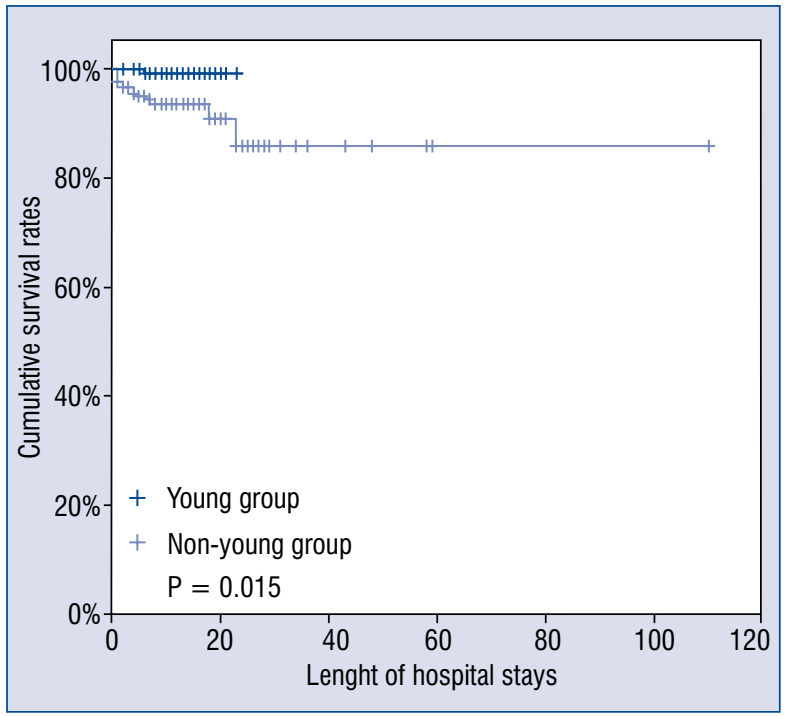

Figure 1. Kaplan-Meier curves estimated of the cumulative survival rates between the two groups.

For the patients with intracoronary thrombus, we inclined to use transcatheter thrombus aspiration, intracoronary tirofiban, intracoronary balloon dilatation or delayed stenting according to the burden of thrombus. Delayed stenting is safe and feasible for STEMI patients with high-burden thrombus who have undergone initial thrombus aspiration, and may be associated with better immediate myocardial perfusion, more left ventricular function recovery, and less occurrence of major adverse cardiovascular events at 1-year follow-up [21]. Although the incidence of intracoronary thrombus was high in the young group, lower mortality and shorter length of hospital stay were more common in the young group than that in the non-young group. Results of this study indicated that intracoronary thrombus per se, might not be a risk factor of major adverse cardiovascular events.

In the previous studies, favorable hospital outcomes in the young AMI patients were reported $[6,7,22-25]$. The present study showed that mortality, infection and congestive heart failure were lower in the young group than in the non-young group. At the same time, it was found that the prevalence of Killip class I, low level of NT-proBNP, single-vessel lesion and short length of hospital stay were more common in the young group patients. All of these indexes indicated a relatively mild condition and prognosis of the young patients would be better than the non-young patients. Younger age per se, is a significant independent indicator of a favorable prognosis after AMI [24]. The results of the current study were similar with previous studies, which reported that the prevalence of Killip I and single-vessel lesion in the young groups was higher than in the non-young groups $[6,8,10,11]$. Infection and congestive heart failure during hospitalization were more often observed in the non-young group 
Table 5. Multivariate logistic regression analysis of risk factors.

\begin{tabular}{lccrc}
\hline Variables & $\begin{array}{c}\text { Univariate Cox analysis } \\
\text { HR }(95 \% \mathrm{CI})\end{array}$ & $\mathbf{P}$ & $\begin{array}{c}\text { Multivariate Cox analysis } \\
\text { HR (95\% CI) }\end{array}$ & P \\
\hline Age [years] & $1.108(1.064-1.155)$ & 0.000 & $1.180(1.052-1.324)$ & 0.005 \\
Length of hospital stay [day] & $0.558(0.466-0.667)$ & 0.000 & $0.769(0.646-0.916)$ & 0.003 \\
Advanced Killip class (III/IV) & $50.300(20.353-124.310)$ & 0.000 & $33.099(3.846-284.861)$ & 0.001 \\
White blood cell [10 $/ \mathrm{L}]$ & $1.395(1.254-1.551)$ & 0.000 & $1.720(1.264-2.339)$ & 0.001 \\
Lg NT-proBNP & $45.249(11.164-183.408)$ & 0.000 & $69.794(4.157-1171.878)$ & 0.003 \\
\hline
\end{tabular}

$\mathrm{Cl}$ - confidence interval; $\mathrm{HR}$ - hazard ratio; NT-proBNP $-\mathrm{N}$-terminal pro-B-type natriuretic peptide

might have increased the length of hospital stay and indicated an adverse outcome.

\section{Limitations of the study}

Since this study was an observational, retrospective and single-center study, selection bias might be an interference factor. The groups were uneven in size and there were many between-group differences in baseline and preprocedural characteristics. Some issues inherent to this type of study were related to retrospective data collection and analysis of the data. More young patients with AMI enrolled into prospective and multi-center study would be help to confirm our findings. The present study did not focus on the long-term survival data. And survival data should surely be indicated in future studies.

\section{Conclusions}

Compared with the non-young group, the young group was associated with male, smoke, less chronic diseases, lower Killip class on admission, lower level of NT-proBNP, higher level of triglyceride and lower level of HDL-C, single-vessel lesion and intracoronary thrombus. Infection and congestive heart failure were less common observed in young patients than non-young patients during hospitalization. Old age, shorter hospital stay, advanced Killip class III/IV, increased white blood cell and NT-proBNP were independent risk factors for survival in acute STEMI patients during hospitalization.

\section{Funding}

Supported by Jiangsu Provincial Medical Innovation Team; No. CXTDA 2017009.

Conflict of interest: None declared

\section{References}

1. Naghavi M, Abajobir AA, Abbafati C, et al. Global, regional, and national age-sex specific mortality for 264 causes of death, 1980-2016: a systematic analysis for the Global Burden of Disease Study 2016. Lancet. 2017; 390(10100): 1151-1210, doi: 10.1016/ S0140-6736(17)32152-9, indexed in Pubmed: 28919116.

2. Gensini GG. A more meaningful scoring system for determining the severity of coronary heart disease. Am J Cardiol. 1983; 51(3): 606, doi: 10.1016/s0002-9149(83)80105-2, indexed in Pubmed: 6823874 .

3. Zhou M, Wang H, Zeng X, et al. Mortality, morbidity, and risk factors in China and its provinces, 1990-2017: a systematic analysis for the Global Burden of Disease Study 2017. Lancet. 2019; 394(10204): 1145-1158, doi: 10.1016/S0140-6736(19)30427-1, indexed in Pubmed: 31248666.

4. The National Health Commission of the people's Republic of China. China health statistics year book 2020 (in Chinese). Beijing:Publish House of Peking Union Medical College, 2020.

5. Zhang XH, Lu ZL, Liu L. Coronary heart disease in China. Heart. 2008; 94(9): 1126-1131, doi: 10.1136/hrt.2007.132423, indexed in Pubmed: 18703693.

6. Zimmerman FH, Cameron A, Fisher LD, et al. Myocardial infarction in young adults: angiographic characterization, risk factors and prognosis (Coronary Artery Surgery Study Registry). J Am Coll Cardiol. 1995; 26(3): 654-661, doi: 10.1016/07351097(95)00254-2, indexed in Pubmed: 7642855.

7. Kanitz MG, Giovannucci SJ, Jones JS, et al. Myocardial infarction in young adults: risk factors and clinical features. J Emerg Med. 1996; 14(2): 139-145, doi: 10.1016/0736-4679(95)02089-6, indexed in Pubmed: 8740743.

8. Hoit BD, Gilpin EA, Henning H, et al. Myocardial infarction in young patients: an analysis by age subsets. Circulation. 1986; 74(4): 712-721, doi: 10.1161/01.cir.74.4.712, indexed in Pubmed: 3757185.

9. Doughty M, Mehta R, Bruckman D, et al. Acute myocardial infarction in the young: The University of Michigan experience. Am Heart J. 2002; 143(1): 56-62, doi: 10.1067/mhj.2002.120300, indexed in Pubmed: 11773912.

10. Shiraishi J, Kohno Y, Yamaguchi S, et al. AMI-Kyoto Multi-Center Risk Study Group, AMI-Kyoto Multi-Center Risk Study Group. Acute myocardial infarction in young Japanese adults. Circ J. 
2005; 69(12): 1454-1458, doi: 10.1253/circj.69.1454, indexed in Pubmed: 16308491.

11. Schoenenberger AW, Radovanovic D, Stauffer JC, et al. AMIS Plus Investigators. Acute coronary syndromes in young patients: presentation, treatment and outcome. Int J Cardiol. 2011; 148(3): 300-304, doi: 10.1016/j.ijcard.2009.11.009, indexed in Pubmed: 19942306.

12. Sinha SK, Krishna V, Thakur R, et al. Acute myocardial infarction in very young adults: A clinical presentation, risk factors, hospital outcome index, and their angiographic characteristics in North India-AMIYA Study. ARYA Atheroscler. 2017; 13(2): 79-87, indexed in Pubmed: 29026414.

13. Chen Z, Peto R, Zhou M, et al. China Kadoorie Biobank (CKB) collaborative group. Contrasting male and female trends in tobacco-attributed mortality in China: evidence from successive nationwide prospective cohort studies. Lancet. 2015; 386(10002): 1447-1456, doi: 10.1016/S0140-6736(15)00340-2, indexed in Pubmed: 26466050.

14. Jinnouchi H, Sakakura K, Wada H, et al. Clinical features of myocardial infarction in young Japanese patients. Int Heart J. 2013; 54(3): 123-128, doi: 10.1536/ihj.54.123, indexed in Pubmed: 23774233.

15. Bęćkowski M, Kowalik I, Jaworski K, et al. Differences in symptomatology and clinical course of acute coronary syndromes in women $\leq 45$ years of age compared to older women. Curr Probl Cardiol. 2021; 46(3): 100508, doi: 10.1016/j.cpcardiol. 2019.100508, indexed in Pubmed: 31898981.

16. Dai J, Lyu S, Song X, et al. Stent Versus Non-Stent in Treating Intermediate Stenosis Culprit Lesions in Acute ST-Segment Elevation Myocardial Infarction Patients. Int Heart J. 2017; 58(3): 357-364, doi: 10.1536/ihj.16-309, indexed in Pubmed: 28539569.

17. Gao M, Zhao W, Zhang Z, et al. Clinical characteristics and outcomes in young patients with ST-segment elevation myocardial infarction after primary percutaneous coronary intervention. Am J Med Sci. 2018; 355(6): 544-552, doi: 10.1016/j. amjms.2018.02.003, indexed in Pubmed: 29891037.
18. Hwang H, Jung WS, Kim J, et al. Comparison of association between physical activity and resting metabolic rate in young and middleaged Korean adults. J Exerc Nutrition Biochem. 2019; 23(2): 16-21, doi: 10.20463/jenb.2019.0012, indexed in Pubmed: 31337201.

19. Hodis HN. Triglyceride-rich lipoprotein remnant particles and risk of atherosclerosis. Circulation. 1999; 99(22): 2852-2854, doi: 10.1161/01.cir.99.22.2852, indexed in Pubmed: 10359725.

20. Spagnoli LG, Bonanno E, Sangiorgi G, et al. Role of inflammation in atherosclerosis. J Nucl Med. 2007; 48(11): 1800-1815, doi: 10.2967/jnumed.107.038661, indexed in Pubmed: 17942804 .

21. Ke D, Zhong W, Fan L, et al. Delayed versus immediate stenting for the treatment of ST-elevation acute myocardial infarction with a high thrombus burden. Coron Artery Dis. 2012; 23(7): 497-506, doi: 10.1097/MCA.0b013e328358a5ad, indexed in Pubmed: 22968214 .

22. Barbash GI, White HD, Modan M, et al. Acute myocardial infarction in the young: the role of smoking. The Investigators of the International Tissue Plasminogen Activator/Streptokinase Mortality Trial. Eur Heart J. 1995; 16: 313-316, doi: 10.1093/ oxfordjournals.eurheartj.a060912.

23. Garoufalis S, Kouvaras G, Vitsias G, et al. Comparison of angiographic findings, risk factors, and long term follow-up between young and old patients with a history of myocardial infarction. Int J Cardiol. 1998; 67(1): 75-80, doi: 10.1016/s0167-5273(98)00194-6, indexed in Pubmed: 9880203.

24. Moccetti T, Malacrida R, Pasotti E, et al. Epidemiologic variables and outcome of 1972 young patients with acute myocardial infarction. Data from the GISSI-2 database. Investigators of the Gruppo Italiano per lo Studio della Sopravvivenza nell'Infarto Miocardico (GISSI-2). Arch Intern Med. 1997; 157(8): 865-869, indexed in Pubmed: 9129546.

25. Morillas P, Bertomeu V, Pabón P, et al. PRIAMHO II Investigators. Characteristics and outcome of acute myocardial infarction in young patients. The PRIAMHO II study. Cardiology. 2007; 107(4): 217-225, doi: 10.1159/000095421, indexed in Pubmed: 16953107. 